\title{
Operación Génesis: reflexiones en torno a la propiedad colectiva indígena y tribal $^{*}$
}

\author{
Operación Génesis: Reflections on Indigenous and Tribal Collective \\ Property \\ Operação Génese: reflexões em torno à propriedade coletiva indígena \\ e tribal
}

\section{SEBASTIÁN LÓPEZ ESCARCENA ${ }^{* *}$}

FECHA DE RECEPCiÓN: 15 DE AGOSTO de 2015. FECHA dE ACEPTACIÓN: 7 DE OCTUBRE DE 2015

Doi: dx.doi.org/10.12804/esj18.01.2016.05

Para citar este artículo: López Escarcena, S. (2016). Operación Génesis: reflexiones en torno a la propiedad colectiva indígena y tribal. Estudios Socio-Jurídicos, 18(1), 137-168. Doi: dx.doi.org/10.12804/esj 18.01.2016.05

\section{RESUMEN}

A partir de la sentencia recaída en Comunidades afrodescendientes desplazadas de la cuenca del río Cacarica (Operación Génesis), este artículo busca replantear algunas de las preguntas que han ido quedando sin respuesta en la jurisprudencia sobre propiedad colectiva de las comunidades indígenas y tribales de la Corte Interamericana de Derechos Humanos. Como en otras de sus decisiones judiciales, en Operación Génesis el Tribunal internacional reiteró ciertos elementos constitutivos de este derecho de propiedad comunal que ha venido desarrollando jurisprudencialmente. Sin embargo, no se pronunció acerca de otros de igual importancia, como los criterios que a su juicio permiten identificar cuándo se está en presencia de un pueblo indígena o tribal y sus tierras y territorios, o de una privación o limitación de su derecho de propiedad colectiva. Si bien Operación Génesis no responde a estas interrogantes, posibilita una necesaria relectura crítica de su jurisprudencia sobre propiedad comunal indígena y tribal destinada a interpelar no solo a la doctrina internacional y comparada, sino también a la Corte misma.

Palabras clave: propiedad, pueblos indígenas y tribales, Corte Interamericana.

* Este trabajo es parte del proyecto Fondecyt Regular № 11113065, adjudicado en 2012 y titulado "La constitucionalización de la propiedad indígena y su coordinación con otras formas de propiedad".

** Profesor asociado de la Facultad de Derecho de la Pontificia Universidad Católica de Chile e investigador asociado (associate fellow/membre associê) del Centro para el Estudio de la Gobernanza Global de la Universidad Católica de Lovaina (Bélgica) y del Instituto de Investigación en Derecho Internacional y Europeo de la Universidad París 1 "Panteón-Sorbona" (Francia). PhD (Edimburgo), LLM (Leiden), abogado y licenciado en Derecho (Católica de Chile). Correo electrónico: rlopeze@uc.cl 


\section{ABSTRACT}

With the judgment on Comunidades afrodescendientes desplazadas de la cuenca del río Cacarica (Operación Génesis) as background, this article aims at reasking some of the questions that have been left unanswered in the case-law on collective property of indigenous and tribal communities of the Inter-American Court of Human Rights. Like in other of its judicial decisions, in Operación Génesis the international tribunal reiterated some of the constitutive elements of this right of communal property that it has been developing jurisprudentially. However, it did not pronounce itself on other elements of equivalent importance, like the criteria that it uses to identify indigenous or tribal peoples and their lands and territories, or the deprivation or limitation of their right to collective property. Even though Operación Génesis does not answer these questions, it allows for a necessary critical rereading of its case-law on indigenous and tribal communal property, destined to challenge not only the comparative and international doctrine, but also for the Court itself.

Keywords: property, indigenous and tribal peoples, Inter-American Court.

\section{RESUMO}

A partir da sentencia recaída em Comunidades afrodescendentes deslocadas do Rio Cacarica (Operação Génese), este artigo busca reformular algumas das perguntas que tem ido ficando sem resposta na jurisprudência sobre propriedade coletiva das comunidades indígenas e tribais da Corte Interamericana de Direitos Humanos. Como em outras de suas decisões judiciais, em Operação Génese o tribunal internacional reiterou alguns elementos constitutivos deste direito de propriedade comunal que tem vido desenvolvendo jurisprudencialmente. No entanto, não se pronunciou sobre outros de igual importância, como são os critérios que a seu juízo permitem identificar quando está-se em presença de um povo indígena e suas terras e territórios, ou de uma privação ou limitação de seu direito de propriedade coletiva. Se bem a Operação Génese não responde a estes interrogantes, possibilita uma necessária releitura crítica de sua jurisprudência sobre propriedade comunal indígena e tribal destinada a interpelar não só à doutrina internacional e comparada, mas também à mesma Corte.

Palavras- chave: Propriedade, Povos indígenas e tribais, Corte Interamericana. 


\section{Introducción}

Comunidades afrodescendientes desplazadas de la cuenca del río Cacarica (Operación Génesis) es una de las últimas sentencias de la Corte Interamericana de Derechos Humanos que se han pronunciado sobre la protección que el Artículo 21 del Pacto de San José de Costa Rica otorga a la propiedad colectiva de los pueblos indígenas y tribales. ${ }^{1}$ En esta decisión judicial, el Tribunal confirma varios criterios interpretativos que ha venido desarrollando en los últimos años para extender la protección de la Convención Americana sobre Derechos Humanos a una forma de propiedad que este tratado inicialmente no contempló. ${ }^{2} \mathrm{Al}$ igual que en sus sentencias anteriores sobre la materia, en Operación Génesis la Corte no resolvió las dudas que su interpretación del Artículo 21 ha dejado sin respuesta desde que empezara a aplicar esta disposición a la propiedad comunal. ¿Qué entiende el Tribunal por pueblos indígenas y tribales?, ¿cuáles son las tierras y los territorios que pueden ser calificados de ancestrales o tradicionales? y ¿qué diferencia hay entre las privaciones de propiedad y las limitaciones o restricciones a este derecho? son algunas de las preguntas que generalmente ha rehuido la Corte en sus sentencias. Al estar últimamente más interesada en clarificar el derecho de consulta indígena y tribal, que en plantearse tales interrogantes, corresponde a la doctrina insistir en estos puntos. ${ }^{3}$

La ampliación de la protección convencional a la propiedad colectiva indígena y tribal es uno de los aspectos más destacados de la interpretación

1 Con posterioridad a Operación Génesis, el Tribunal internacional condenó a otro Estado parte de la Convención Americana de Derechos Humanos por violar el Artículo 21. Ver en general Corte Interamericana de Derechos Humanos, 2014a.

Las sentencias de la Corte Interamericana están disponibles en http://www.corteidh.or.cr/ index.php/es/casos-contenciosos

2 Ver Corte Interamericana de Derechos Humanos (2014b, párrs. 11-12). Ver también Rodríguez-Piñero (2006, 159; 186-187); Forero (2010, pp. 181-185); Rodríguez Garavito y Morris (2010, p. 45); Rodríguez-Piñero (2013a, p. 134); Ruiz Chiriboga y Donoso (2014, pp. 953; 971). Cf. Anaya y Williams (2001, p. 41); Rinaldi (2009, pp. 216-217; 219-221; 247-248).

3 Ver en general Corte Interamericana de Derechos Humanos (2007; 2012a).

Sobre el derecho de consulta indígena y tribal en el Derecho Internacional ver Organización Internacional del Trabajo (2009, pp. 59-66; 107-115); Pasqualucci (2009, pp. 86-91); Forero (2010, pp. 199-203); Rodríguez Garavito y Morris (2010, pp. 31-35; 41-83); Pentassuglia (2011, pp. 176182); Salmón (2011, pp. 219-223); Schettini (2012, pp. 71-81); Ruiz Chiriboga y Donoso (2014, pp. 984-993). Ver también Anaya y Williams (2001, pp. 77-84); Anaya (2005, pp. 7-17); Gómez (2006, pp. 142-144; 146-149); Olivares (2013); Patiño (2014). 
que la Corte ha hecho del Artículo 21. En virtud de esta, los Estados parte del Pacto de San José de Costa Rica tienen el deber de respetar un derecho que es fundamental para la supervivencia de pueblos generalmente postergados y desvalidos, cuya identidad comunal depende en gran medida de la relación material y espiritual que mantengan con ciertos territorios y sus recursos. No obstante, la indefinición conceptual sobre la que se estructura la jurisprudencia interamericana que se refiere a este tipo de propiedad dificulta el cumplimiento de las obligaciones que el Artículo 21 impone a los Estados parte de la Convención Americana. El estudio de Operación Génesis constituye, por tanto, una invitación a revisar de una manera inductiva-analítica el conjunto de las decisiones judiciales de la Corte Interamericana relativas a la propiedad comunal de los pueblos indígenas y tribales, a fin de replantear ciertas cuestiones cuya aclaración es indispensable para el adecuado cumplimiento de las obligaciones que su jurisprudencia establece.

\section{Comunidades afrodescendientes desplazadas}

El departamento del Chocó queda en la región del Urabá, ubicada en el noroeste de Colombia, en la unión entre Centro y Sudamérica. Es un área selvática biodiversa, de gran riqueza hídrica. ${ }^{4}$ Uno de sus ríos es el Cacarica, en cuya cuenca habitan, sobre todo, descendientes de africanos traídos como esclavos durante la Colonia, que se fueron asentando en esa región una vez abolida la esclavitud en el siglo XIX. ${ }^{5}$ Estas comunidades de afrodescendientes tienen una economía de autosubsistencia y se caracterizan por ser vulnerables, marginales y segregadas del resto de la población de Colombia. ${ }^{6}$ Urabá es una región donde el Estado tiene poca presencia. Eso, sumado a su ubicación y sus características geográficas, le confiere una gran importancia en el conflicto armado colombiano, en particular para los grupos ilegales que trafican drogas y armas en la región. La acción de dichos grupos paramilitares y guerrilleros provocó desplazamientos masivos

\footnotetext{
4 Ver Corte Interamericana de Derechos Humanos (2013b, párrs. 83-4).

5 Ver Corte Interamericana de Derechos Humanos (2013b, párr. 85).

6 Ver Corte Interamericana de Derechos Humanos (2013b, párr. 87).
} 
en esta zona a partir de mediados de la década de $1990 .^{7}$ En este contexto, entre el 24 y el 27 de febrero de 1997, el Ejército, la Fuerza Aérea y la Armada de Colombia ejecutaron la llamada Operación Génesis en el área general de los ríos Salaquí y Truandó, cercana a los territorios de las comunidades afrodescendientes de la cuenca del Cacarica. Aprovechando que la operación colombiana estaba dirigida contra la guerrilla, los paramilitares realizaron un conjunto de acciones armadas en el departamento del Chocó denominadas Operación Cacarica. Como resultado de lo anterior, murió una persona y cientas fueron desplazadas, muchas de las cuales pertenecían a las comunidades afrodescendientes que habitan la cuenca de este río del Urabá. ${ }^{8}$

En su solicitud ante la Corte Interamericana, la Comisión alegó violaciones a las siguientes disposiciones de la Convención Americana sobre Derechos Humanos: Artículos 4 y 5 (derechos a la vida y a la integridad personal) en relación con el Artículo 1.1 (obligación de respetar los derechos reconocidos convencionalmente); Artículo 22 (derecho a la circulación y residencia) en relación con los Artículos 1.1, 5, 11, 17, 19, 21 y 24 (protección de la honra y la dignidad, protección a la familia, derechos del niño, derecho a la propiedad privada e igualdad ante la ley); Artículos 8 y 25 (garantías judiciales y protección judicial) en relación con el Artículo 1.1. ${ }^{9}$ Respecto al Artículo 21, la Comisión Interamericana solicitó a la Corte que declare la responsabilidad internacional de Colombia por la violación del derecho a la propiedad colectiva de las comunidades afrodescendientes sobre los territorios que han poseído ancestralmente en la cuenca del Cacarica y que el Estado les ha reconocido, como consecuencia de los desplazamientos forzados derivados de la Operación Génesis y de la Operación Cacarica y de las explotaciones ilegales de recursos naturales efectuados por empresas privadas con el permiso o la tolerancia de Colombia. ${ }^{10}$

La Sentencia de la Corte Interamericana resolvió en contra del Estado demandado algunos de los alegados incumplimientos de derechos reco-

7 Ver Corte Interamericana de Derechos Humanos (2013b, párrs. 87-97).

8 Ver Corte Interamericana de Derechos Humanos (2013b, párrs. 1, 81, 100-102, 107-111). Ver también Corte Interamericana de Derechos Humanos (2013b, párrs. 117-196).

9 Ver Corte Interamericana de Derechos Humanos (2013b, párr. 3). Ver también Corte Interamericana de Derechos Humanos (2013b, párrs. 1-2, 4).

10 Ver Corte Interamericana de Derechos Humanos (2013b, párrs. 1, 81). 
nocidos convencionalmente. En primer lugar, el Tribunal consideró que Colombia violó los derechos a la vida y a la integridad personal de ciertos miembros de las comunidades afrodescendientes de la cuenca del Cacarica. Esta responsabilidad, sin embargo, no provino de la ejecución por las Fuerzas Armadas colombianas de la Operación Génesis, cuyos bombardeos se efectuaron a varios kilómetros de los lugares habitados por estos pueblos tribales. ${ }^{11}$ Conforme a la sentencia, al haber colaborado con los grupos paramilitares que ejecutaron la Operación Cacarica o, al menos, haber permitido con su aquiescencia que se llevara a efecto, Colombia es responsable de la tortura y muerte de uno de los miembros de las comunidades afrodescendientes y de los desplazamientos forzados de estos pueblos tribales debido a dicha operación paramilitar. ${ }^{12}$ En segundo lugar, la Corte estimó que las medidas de asistencia humanitaria proporcionadas por Colombia durante los desplazamientos y el posterior retorno de las comunidades afrodescendientes a la cuenca del río Cacarica fueron insuficientes. Vale decir, en violación del derecho a la integridad personal, los derechos de circulación y residencia y los derechos de los niños. ${ }^{13}$ Finalmente y en tercer lugar, el Tribunal internacional resolvió que Colombia es responsable de incumplir los derechos a las garantías judiciales y a la protección judicial, al no haber investigado con la debida diligencia a los integrantes de las Fuerzas Armadas colombianas y de los grupos paramilitares que ejecutaron las operaciones Génesis y Cacarica, respectivamente. ${ }^{14}$

La Corte Interamericana no solo declaró la responsabilidad internacional de Colombia por violar los derechos mencionados, sino que también falló en contra del Estado demandado por incumplir lo dispuesto en el Artículo 21 del Pacto de San José de Costa Rica. La sentencia partió por ubicar geográficamente a las comunidades afrodescendientes de la cuenca del río Cacarica, para después agregar:

11 Ver Corte Interamericana de Derechos Humanos (2013b, párrs. 237-240). Ver también Corte Interamericana de Derechos Humanos (2013b, párrs. 227-236).

12 Ver Corte Interamericana de Derechos Humanos (2013b, párrs. 280-281, 290, 486). Ver también Corte Interamericana de Derechos Humanos (2013b, párrs. 241-279, 283-289).

13 Ver Corte Interamericana de Derechos Humanos (2013b, párrs. 323-324, 329-331, 486). Ver también Corte Interamericana de Derechos Humanos (2013b, párrs. 315-322, 327-328).

14 Ver Corte Interamericana de Derechos Humanos (2013b, párrs. 386-7, 397, 486).Ver también Corte Interamericana de Derechos Humanos (2013b, párrs. 368-385, 388-96). 
[...] que en el contexto del derecho de propiedad de miembros de los pueblos indígenas, el artículo 21 de la Convención protege la vinculación estrecha que los pueblos indígenas y otras comunidades o pueblos tribales, como pueden ser las afrodescendientes, guardan con sus tierras, así como con los recursos naturales de los territorios ancestrales y los elementos incorporales que se desprendan de ellos. Debido precisamente a esa conexión intrínseca que los integrantes de los pueblos indígenas y tribales tienen con su territorio, la protección del derecho a la propiedad, uso y goce sobre éste es necesaria para garantizar su supervivencia. ${ }^{15}$

Esta aseveración fue acompañada de referencias a otras decisiones judiciales sobre pueblos indígenas o tribales del mismo Tribunal: Comunidad Mayagna (Sumo) Awas Tingni, Comunidad indígena Yakye Axa y Pueblo indígena Kichwa de Sarayaku (Corte Interamericana de Derechos Humanos, 2000; 2001 b; 2005b; 2012a). ${ }^{16}$ La Corte Interamericana destacó que la propiedad colectiva de las comunidades afrodescendientes de la cuenca del Cacarica está protegida por el Artículo 21 y también por la legislación interna colombiana que, desde 1967, reconoce este tipo de propiedad para los territorios que han ocupado ancestralmente las "comunidades negras". ${ }^{17}$

El Tribunal no tuvo dificultad en concluir que las destrucciones y los saqueos que acompañaron a la Operación Cacarica y el abandono en el que quedaron los territorios comunitarios tras los desplazamientos forzados de sus habitantes, afectaron la propiedad individual y comunal de los pueblos tribales de ese sector del Chocó. ${ }^{18}$ Como indicó la Sentencia:

[...] teniendo en cuenta las circunstancias particulares del caso, el contexto en el cual ocurrieron los hechos y el hecho que el Estado no controvierte las consideraciones de derecho relacionadas con la presenta [sic]

15 Corte Interamericana de Derechos Humanos (2013b., párr. 346). Ver Corte Interamericana de Derechos Humanos (2013b, párr. 345). Ver también Rinaldi (2009, pp. 228-231).

16 Ver Corte Interamericana de Derechos Humanos (2001b, párr. 148; 2005b, párrs. 124-5, 135, 137; 2012a, párrs. 145-146).

Si bien la Sentencia se refiere a la decisión sobre excepciones preliminares de Awas Tingni, el párrafo citado se ubica en la sentencia de fondo de dicho caso. Ver Corte Interamericana de Derechos Humanos (2000).

17 Ver Corte Interamericana de Derechos Humanos (2013b, párr. 347).

18 Ver Corte Interamericana de Derechos Humanos (2013b, párr. 351). Ver también Corte Interamericana de Derechos Humanos (2013b, párrs. 350, 352). 
violación a este derecho, el Tribunal considera que el Estado es responsable por los actos relacionados con incursiones paramilitares que causaron o propiciaron la violación del derecho a la propiedad colectiva, contenido en el artículo 21 de la Convención, en perjuicio de los miembros de las comunidades desplazadas del Cacarica. ${ }^{19}$

No es de extrañar que, en las consideraciones de esta Sentencia, la Corte se hubiera referido a Masacre de Ituango y a Masacre de Santo Domingo, dos controversias relacionadas con el conflicto armado colombiano y falladas en contra del Estado demandado. ${ }^{20}$ En estos casos, así como en Operación Génesis, Colombia incumplió el Artículo 21 por medio de comportamientos que constituyeron violaciones de disposiciones convencionales centrales al sistema de protección que ofrece el Pacto de San José de Costa Rica, como los Artículos 4 y 5, que protegen los derechos a la vida y a la integridad personal de toda persona sujeta a la jurisdicción de los Estados parte de este Tratado. ${ }^{21}$

En cuanto a las explotaciones ilegales de recursos naturales efectuados por empresas privadas en la cuenca del Cacarica con el permiso o la tolerancia de Colombia, el Tribunal resolvió que:

[...] han desconocido la ley de negritudes y su decreto reglamentario que regulan la participación de las comunidades en el diseño, coordinación y ejecución de los planes programas y proyectos de desarrollo económico en sus territorios, así como los roles de las autoridades negras en la administración y manejo de sus territorios. ${ }^{22}$

Para llegar a esta conclusión, la Corte tuvo en cuenta criterios ya desarrollados en los casos Yakye Axa, Comunidad indígena Sawhoyamaxa y Kichwa de Sarayaku, a los que citó al hacer la siguiente declaración:

19 Corte Interamericana de Derechos Humanos (2013b, párr. 353). Ver también Corte Interamericana de Derechos Humanos (2013b, párr. 486).

20 Ver Corte Interamericana de Derechos Humanos (2013b, párrs. 349-350, 352). Ver también Corte Interamericana de Derechos Humanos (2006c, párr. 181; 2012d, párrs. 271-273).

21 Ver la Convención Americana sobre Derechos Humanos, art. 1.1.

22 Corte Interamericana de Derechos Humanos (2013b, párr. 355). 
La conexión entre el territorio y los recursos naturales que han usado tradicionalmente los pueblos indígenas y tribales y que son necesarios para su supervivencia física y cultural, así como el desarrollo y continuidad de su cosmovisión, está protegida por el artículo 21 de la Convención. Ello, para garantizar que puedan continuar viviendo su modo de vida tradicional y que su identidad cultural, estructura social, sistema económico, costumbres, creencias y tradiciones distintivas serán respetadas, garantizadas y protegidas por los Estados. La falta de acceso a los territorios puede impedir a las comunidades indígenas usar y disfrutar de los recursos naturales necesarios para procurar su subsistencia, mediante sus actividades tradicionales, acceder a los sistemas tradicionales de salud y otras funciones socioculturales. Eso puede exponerlos a condiciones de vida precarias o infrahumanas, a mayor vulnerabilidad ante enfermedades y epidemias, así como someterlos a situaciones de desprotección extrema. ${ }^{23}$

En virtud de las consideraciones anteriores, el Tribunal concluyó que las explotaciones de la propiedad colectiva de las comunidades afrodescendientes del Cacarica fueron llevadas a cabo en forma ilegítima, que las autoridades colombianas no protegieron este derecho a pesar de haber tomado conocimiento de la ilegalidad de dichas explotaciones por medio de visitas in situ y que los recursos administrativos o judiciales internos disponibles no fueron efectivos para remediar esta situación. ${ }^{24}$ Todo esto constituyó una violación de Colombia al derecho de propiedad colectiva, consagrado en el Artículo 21 de la Convención Americana sobre Derechos Humanos. ${ }^{25}$

\section{Operación Génesis en su contexto}

Al igual que en Masacre Plan de Sánchez y Comunidad Moiwana, en Operación Génesis la Corte Interamericana condenó al Estado demandado por incumplir el Artículo 21, por medio de conductas constitutivas, ante

23 Corte Interamericana de Derechos Humanos (2013b., párr 354). Ver Corte Interamericana de Derechos Humanos (2006b párrs. 73.61-74; 2010a, párrs. 124, 135, 137, 164; 2012a, párrs. 146-147).

24 Ver Corte Interamericana de Derechos Humanos (2013b, párr. 356). Ver también Corte Interamericana de Derechos Humanos (2013b, párrs. 404-410).

25 Ver Corte Interamericana de Derechos Humanos (2013b, párrs. 358, 486). Ver también Corte Interamericana de Derechos Humanos (2013b, párrs. 357, 458-460, 470-475). 
todo, de violaciones a otros derechos convencionales. ${ }^{26}$ Tal vez por este motivo, su Sentencia no se apartó de criterios interpretativos ya establecidos en los otros casos de propiedad colectiva indígena y tribal que ha fallado, por lo que no permite aclarar los cuestionamientos que surgen de su corpus jurisprudencial en esta materia y que no han sido debidamente despejados. Como el texto del Artículo 21 no se refiere a los pueblos indígenas y tribales ni a sus derechos de propiedad comunal, consulta e identidad cultural, la Corte ha tenido que recurrir a otros tratados e instrumentos jurídicos, a la jurisprudencia internacional extra interamericana y al Derecho Comparado para fundamentar criterios que va reconociendo y confirmando, sentencia tras sentencia. En otras palabras, ante el silencio convencional, la Corte ha articulado estos derechos de los pueblos indígenas y tribales con base en dos pilares: los principios de interpretación evolutiva y pro homine, por un lado y los fenómenos de fertilización cruzada y diálogo judicial, por otro. ${ }^{27}$

En el sistema interamericano, la propiedad colectiva indígena y tribal es un derecho jurisprudencial. Operación Génesis reiteró algunos de sus elementos constitutivos, como la estrecha relación de los pueblos indígenas y tribales con sus tierras y recursos naturales, de la cual dependen su identidad cultural y subsistencia, además del derecho de participación que tienen sus miembros en la elaboración y ejecución de los proyectos que afecten sus territorios ancestrales. ${ }^{28}$ Sin embargo, la Sentencia no aclaró qué es un pueblo tribal, cómo pueden identificarse sus tierras y territorios tradicionales, o qué diferencia a las privaciones de las limitaciones o restric-

26 Ver en general Corte Interamericana de Derechos Humanos (2004a; 2005a). Ver también Corte Interamericana de Derechos Humanos (2006c; 2011b; 2012b; 2012c; 2012d; 2013a).

27 Sobre los principios de interpretación evolutiva y más favorable a la persona, ver Anaya y Williams (2001, pp. 41-42); Rodríguez-Piñero (2006, pp. 186-187); Weckel y Rinaldi (2008, pp. 423-424); López-Murcia y Maldonado (2009, p. 78); Rinaldi (2009, pp. 219-220; 226-228); Forero (2010, pp. 181-5); Rodríguez-Piñero (2013a, pp. 128-131); De Carvalho Ramos (2014a, pp. 100109); De Carvalho Ramos (2014b, pp. 103-115). Ver también Nash (2013); Bjorge (2014); Rodríguez (2014).

La fertilización cruzada y el diálogo judicial son comunes en el Derecho Internacional, por lo que no es algo se restrinja al área de derechos humanos.

Para el caso del Derecho Internacional de la inversión ver López Escarcena (2014, pp. 186187). Ver en general Commission (2007); Paulsson (2010).

Respecto del Derecho Internacional de los derechos humanos, ver Rodríguez Garavito y Morris (2010, p. 45); Pentassuglia (2011, pp. 180-182; 190; 199-202); Rodríguez-Piñero (2013b, pp. 197 200). Ver en general Nogueira (2012); Burgorgue-Larsen (2013); Ferrer y Herrera (2013); Nogueira (2013); Aguilar (2014); y Nogueira (2014).

28 Ver Corte Interamericana de Derechos Humanos (2013b, párrs. 345-346, 354-355). 
ciones que puede sufrir su derecho de propiedad comunal. Aun cuando los intentos por describir a los diversos pueblos indígenas y tribales en definiciones omnicomprensivas han fracasado, existen criterios identificadores reconocidos por la doctrina. ${ }^{29}$ En la década de 1980, el relator especial de la Subcomisión sobre la Prevención de la Discriminación y Protección de las Minorías de la Comisión de Derechos Humanos de la ONU ofreció una noción general de pueblos indígenas. José Martínez Cobo señaló en su definición que:

Son comunidades, pueblos y naciones indígenas los que, teniendo una continuidad histórica con las sociedades anteriores a la invasión y precoloniales que se desarrollaron en sus territorios, se consideran distintos de otros sectores de las sociedades que ahora prevalecen en esos territorios o en partes de ellos. Constituyen ahora sectores no dominantes de la sociedad y tienen la determinación de preservar, desarrollar y transmitir a futuras generaciones sus territorios ancestrales y su identidad étnica como base de su existencia continuada como pueblos, de acuerdo con sus propios patrones culturales, sus instituciones sociales y sistemas legales.

Esa continuidad histórica puede consistir en la continuación, durante un período prolongado que llegue hasta el presente, de uno o más de los siguientes factores:

a) ocupación de las tierras ancestrales o al menos de parte de ellas;

b) ascendencia común con los ocupantes originales de esas tierras;

c) cultura en general, o en ciertas manifestaciones específicas (tales como religión, vida bajo un sistema tribal, pertenencia a una comunidad indígena, trajes, medios de vida, estilo de vida, etc.);

d) idioma (ya se utilice como lengua única, como lengua materna, como medio habitual de comunicación en el hogar o en la familia o como lengua principal, preferida, habitual, general o normal);

29 Ver Swepston (1990, pp. 695-696); Kingsbury (1998, pp. 414-416; 419-428; 446-455); Wiessner (1999, pp. 110-115); Thornberry (2002, pp. 33-60); Anaya (2004, pp. 3-5); RodríguezPiñero (2005, pp. 39-52; 145-172; 321-322; 338-341); Eide (2006, pp. 186-188); Aguilar (2007, pp. 307-407); Dannenmaier (2008, pp. 58-63); Henriksen (2008, pp. 5-18); Rinaldi (2009, pp. 228-229); UN Permanent Forum on Indigenous Peoples (2009, pp. 4-7); Del Toro (2010, pp. 56-57); Marcelli (2011, pp. 29-40); Gaete (2012). 
e) residencia en ciertas partes del país o en ciertas regiones del mundo;

f) otros factores pertinentes.

Desde el punto de vista individual, se entiende por persona indígena toda persona que pertenece a esas poblaciones indígenas por autoidentificación como indígena (conciencia de grupo) y es reconocida y aceptada por esas poblaciones como uno de sus miembros (aceptación por el grupo).

Eso preserva para esas comunidades el derecho y el poder soberanos de decidir quién pertenece a ellas, sin injerencia exterior. ${ }^{30}$

En 1995, el Grupo de Trabajo sobre los Pueblos Indígenas de la ONU, le pidió a su presidenta que preparara un informe con criterios para una definición de estos. Erica-Irene Daes redactó el documento solicitado y, sin precisar qué se entiende por pueblo indígena, insistió en algunos de los factores del concepto de Martínez Cobo que han sido aceptados por las organizaciones internacionales y los expertos en el tema. Los criterios que mencionó Daes son:

a) la prioridad en el tiempo por la que respecta a la ocupación y el uso de determinado territorio;

b) la perpetuación voluntaria de la distinción cultural, que puede incluir los aspectos del idioma, la organización social, la religión y los valores espirituales, los modos de producción, las leyes e instituciones;

c) la conciencia de la propia identidad, así como su reconocimiento por otros grupos, o por las autoridades estatales, como una colectividad distinta; y

30 UN Doc. PFII/2004/WS.1/3, traducción no oficial al castellano, párr. 2, disponible en http://www.un.org/esa/socdev/unpfii/documents/workshop_data_background_es.htmhttp://www. un.org/esa/socdev/unpfii/documents/workshop_data_background_es.htm consulta del 15/8/2015. El estudio sobre el problema de la discriminación contra las poblaciones indígenas de Martínez Cobo comenzó en 1972 y terminó en 1986. Consta en los siguientes documentos publicados por la ONU:

UN Doc. E/CN.4/Sub.2/476/Add.14; UN Doc. E/CN.4/Sub.2/476/2/Add.5; UN Doc. E/CN.4/Sub.2/1982/2/Add.1-6; UN Doc. E/CN.4/Sub.2/1982/2/Add.6; UN Doc. E/CN.4/ Sub.2/1983/21/Add.1-8; y UN Doc. E/CN.4/Sub.2/1986/7.

Ver Kingsbury (1998, pp. 419-420); Wiessner (1999, pp. 110-111); Eide (2006, pp. 163-164); Bengoa (2007, p. 282); Thornberry (2002, pp. 47-50); Rodríguez-Piñero (2005, p. 262); Aguilar (2007, pp. 342-349); Dannenmaier (2008, p. 59); Henriksen (2008, pp. 5-6); Marcelli (2011, p. 34). 
d) una experiencia de sometimiento, marginación, desposeimiento, exclusión o discriminación, independientemente de que estas condiciones persistan o no. ${ }^{31}$

Subrayó Daes en su informe que:

Los factores señalados no constituyen ni pueden constituir una definición exhaustiva. Más bien, representan factores que pueden encontrarse, en mayor o menor grado, en diferentes regiones y en diferentes contextos nacionales y locales. Así, pueden servir de orientación general para la adopción de decisiones razonables en la práctica. ${ }^{32}$

Según este informe, no habría ninguna razón que justifique distinguir entre pueblos indígenas y tribales en la práctica de la ONU. ${ }^{33}$ La Corte Interamericana tampoco ha hecho esta distinción, como se desprende de Moiwana, Pueblo Saramaka y Operación Génesis. ${ }^{34}$

Sin citar el Artículo 1.2 del Convenio 169 de la Organización Internacional del Trabajo (OIT), la Corte Interamericana declaró en Saramaka y Comunidad Indígena Xákmok Kásek algo similar a lo que el tratado de la OIT señala en esa disposición: que no es el Tribunal ni el Estado demandado el llamado a establecer cómo se identifica una comunidad indígena o tribal. Al ser "un hecho histórico social que hace parte de su autonomía", corresponde a la comunidad respectiva determinar su nombre y composición. ${ }^{35}$ Tal vez esto explique por qué en Awas Tingni, Moiwana, Yakye

31 UN Doc. E/CN.4/Sub.2/AC.4/1996/2, traducción oficial al castellano, párr. 69. Disponible en http://daccess-dds-ny.un.org/doc/UNDOC/GEN/G96/129/83/PDF/G9612983. pdf?OpenElement

Ver Wiessner (1999, pp. 114-115); Dannenmaier (2008, pp. 60-61).

32 UN Doc. E/CN.4/Sub.2/AC.4/1996/2, traducción oficial al castellano, párr. 70.

Ver Wiessner (1999, p. 114); Aguilar (2007, pp. 308-309).

33 UN Doc. E/CN.4/Sub.2/AC.4/1996/2, traducción oficial al castellano, párr. 72.

34 Ver en general Corte Interamericana de Derechos Humanos (2005a; 2007; 2013b).

35 Corte Interamericana de Derechos Humanos (2010a, parr. 37). Ver Corte Interamericana de Derechos Humanos (2007, párr. 164).

El Artículo 1.2 del Convenio № 169 de la OIT indica: "La conciencia de su identidad indígena o tribal deberá considerarse un criterio fundamental para determinar los grupos a los que se aplican las disposiciones del presente Convenio".

Respecto a este tratado ver Swepston (1990); Thornberry (2002, pp. 339-367); Anaya (2004, pp. 53-61; 226-228); Gómez (2006, pp. 133-151); Aguilar (2007, pp. 62-69); Bengoa (2007, pp. 270-275); Dannenmaier (2008, pp. 69-70); UN Permanent Forum on Indigenous Peoples (2009, 
Axa, Sawhoyamaxa, Saramaka y Xákmok Kásek, la Corte no indicó qué entiende por pueblos, tierras y territorios indígenas y tribales, optando simplemente por valerse de declaraciones testimoniales, informes periciales o la regulación interna correspondiente para acreditar esta calidad. ${ }^{36}$ Lo mismo ocurrió en Operación Génesis. ${ }^{37}$ Inspirada en el Artículo 1.1 del Convenio 169, la Corte describió en Saramaka a los pueblos tribales como no indígenas a la región que habitan, pero que comparten ciertas características con dichos pueblos "como tener tradiciones sociales, culturales y económicas diferentes de otras secciones de la comunidad nacional, identificarse con sus territorios ancestrales y estar regulados, al menos en forma parcial, por sus propias normas, costumbres o tradiciones". ${ }^{38}$ La noción de Saramaka volvió a ser utilizada por la Corte años después en Kichwa de Sarayaku, esta vez con una referencia expresa al Artículo 1.1 del Convenio $N^{\circ} 169$ y para un caso relativo a un pueblo indígena. ${ }^{39}$ ¿Quiere decir esto que el Tribunal prefiere alejarse del carácter originario de estas comunidades, para centrar su análisis en las condiciones sociales, culturales y económicas que los distinguen del resto de la población de un Estado y en las costumbres, tradiciones o normas especiales que los rigen?

Lo anterior no es un asunto meramente teórico. El aspecto histórico no solo distingue a los pueblos indígenas de los tribales, sino que los diferencia a ambos de otras minorías, cuyos derechos son únicamente de

pp. 200-201); Xanthaki (2010, pp. 67-91); Marcelli (2011, pp. 69-77); Hervé y Pérez (2012, pp. 23 31); Olivares (2013, pp. 189-191); Meza-Lopehandía (2014). Ver en general Rodríguez-Piñero (2005)

36 Ver Corte Interamericana de Derechos Humanos (2001b, párrs. 75-103; 2005a, párrs. $75-$ 86; 2005b, párrs. 33-50; 2006b, párrs. 34-49, 73; 2007, párrs. 63-76, 78-84; 2010a, párrs. 15-26, 37-44, 56-79, 94-107). Ver también Anaya y Williams (2001, pp. 46-47); Weckel y Rinaldi (2008, pp. 421-423); Rinaldi (2009, pp. 221; 225-226).

37 Ver Corte Interamericana de Derechos Humanos (2013b, párrs. 43-196). Ver también Corte Interamericana de Derechos Humanos (2014a, párrs. 46-105).

38 Corte Interamericana de Derechos Humanos (2007, párr. 79).

El Artículo 1.1. del Convenio $N^{\circ} 169$ de la OIT señala:

"1. El presente Convenio se aplica:

a) a los pueblos tribales en países independientes, cuyas condiciones sociales, culturales y económicas les distingan de otros sectores de la colectividad nacional y que estén regidos total o parcialmente por sus propias costumbres o tradiciones o por una legislación especial;

b) a los pueblos en países independientes, considerados indígenas por el hecho de descender de poblaciones que habitaban en el país o en una región geográfica a la que pertenece el país en la época de la conquista o la colonización o del establecimiento de las actuales fronteras estatales y que, cualquiera que sea su situación jurídica, conservan todas sus propias instituciones sociales, económicas, culturales y políticas, o parte de ellas".

39 Ver Corte Interamericana de Derechos Humanos (2012a, párr. 163). 
carácter individual y no de naturaleza colectiva ${ }^{40}$ Esto ha pasado de una simple declaración jurisprudencial abstracta a ser un principio con implicaciones prácticas en el sistema interamericano de derechos humanos. ${ }^{41}$ Así se desprende de la sentencia de la Corte en Kichwa de Sarayaku, donde el Tribunal consideró como parte lesionada y beneficiaria de las reparaciones correspondientes al pueblo indígena y no a sus integrantes, como lo había hecho en los casos de propiedad comunal que había fallado con anterioridad. ${ }^{42}$ Este criterio ya había sido adelantado por el juez Eduardo Vio Grossi, en su voto concurrente de Xákmok Kásek. ${ }^{43}$ En Operación Génesis, la Corte volvió a estimar como parte lesionada y beneficiaria de las reparaciones que dictó a los integrantes de la comunidad de afrodescendientes de la cuenca del río Cacarica y no al pueblo tribal mismo. ${ }^{44} \mathrm{El}$ principio propuesto por el juez Vio en Xákmok Kásek y adoptado por el Tribunal en Kichwa de Sarayaku, solo estuvo unos meses en entredicho. En Pueblos indígenas Kuna de Madungandí y Emberá de Bayano, la Corte tomó nota de la recomendación de la Comisión Interamericana "de reparar en el ámbito colectivo e individual las consecuencias de las violaciones a los derechos humanos determinadas". ${ }^{45}$ Sin embargo, a pesar de reconocer en forma expresa que las comunidades afectadas y sus miembros eran la parte lesionada del caso, el Tribunal consideró únicamente a estos últimos como beneficiarios de las reparaciones ordenadas, al ser las "víctimas de las violaciones declaradas". ${ }^{46}$

40 Ver Henriksen (2008, pp. 9-11); Del Toro (2010, p. 57); Marcelli (2011, pp. 29-36). Ver también Thornberry (2002, pp. 52-55); Aguilar (2007, pp. 359-368); Gajardo (2014, p. 53).

Cf. Bengoa (2007, pp. 256-268; 272-274; 291-295).

41 Ver Rodríguez-Piñero (2013b, pp. 174-176); Gajardo (2014, pp. 45-46; 60-63); Ruiz Chiriboga y Donoso (2014, pp. 955-957; 972-973). Ver también Ruiz Chiriboga (2006, pp. 4647); Dhommeaux (2009, pp. 192-194); Rinaldi (2009, p. 223); Dulitzky (2010, pp. 57-58); Gonza (2014, 510-512; 521).

42 Ver Corte Interamericana de Derechos Humanos (2012a, párrs. 231, 284, 341). Cf. Corte Interamericana de Derechos Humanos (2001b, párr. 713; 2005a, párrs. 176, 233; 2005b, párr. 242; 2006b, párrs. 242, 248; 2007, párrs. 188-189, 214; 2010a, párrs. 278, 337).

43 Ver Corte Interamericana de Derechos Humanos (2010b, párrs. 21-23).

44 Ver Corte Interamericana de Derechos Humanos (2013b, párrs. 415, 486).

45 Corte Interamericana de Derechos Humanos (2014a, párr. 211). Ver Corte Interamericana de Derechos Humanos (2014b, párrs. 210, 212-213).

46 Corte Interamericana de Derechos Humanos (2014a, párr. 209). 
En consonancia con la aproximación de la OIT al respecto, la Comisión Interamericana ha declarado que "[n]o existe una definición precisa de 'pueblos indígenas' en el derecho internacional y la posición prevaleciente indica que dicha definición no es necesaria para efectos de proteger sus derechos humanos". ${ }^{47}$ Conforme a la Comisión, el Derecho Internacional proporciona algunos criterios útiles para establecer cuándo un grupo de personas puede ser considerado como pueblo indígena. ${ }^{48}$ Debido a que la Declaración de la ONU sobre los Derechos de los Pueblos Indígenas apenas consigna en su Artículo 33.1 que "los pueblos indígenas tienen derecho a determinar su propia identidad o pertenencia conforme a sus costumbres y tradiciones", estos criterios estarían consagrados sobre todo en el Artículo 1 del Convenio 169.49 El informe de Erica-Irene Daes de 1996 confirmaría los criterios de la OIT. ${ }^{50}$ Según la Comisión, estas consideraciones también serían aplicables a los pueblos tribales. ${ }^{51}$ De este modo:

Un elemento clave para la determinación de cuándo un determinado grupo se puede considerar como indígena o tribal es la continuidad histórica de su presencia en un determinado territorio y -para el caso de los pueblos indígenas- su vinculación ancestral con las sociedades que preexistían a un período de colonización o conquista. Ello no implica, sin embargo, que los pueblos indígenas o tribales sean sociedades estáticas que permanecen idénticas a sus antecesores. Por el contrario, en tanto

47 Comisión Interamericana de Derechos Humanos (2010, p. 10).

Ver también Organización Internacional del Trabajo (2009, p. 9).

48 Ver Comisión Interamericana de Derechos Humanos (2010, p. 10).

49 Ver Comisión Interamericana de Derechos Humanos (2010, pp. 10-1). Ver también Organización Internacional del Trabajo (2009, pp. 9-23); UN Permanent Forum on Indigenous Peoples (2009, pp. 5-6); Marcelli (2011, pp. 31-33; 38).

La Declaración de la ONU sobre los Derechos de los Pueblos Indígenas fue aprobada por la Asamblea General de esta organización internacional en su Res. 61/295 de 2007.

Sobre esta declaración de la ONU ver Bengoa (2007, pp. 275-281; 287-291; 295-298); Wiessner (2008, pp. 1159-1166); Zalaquett (2008, pp. 139-48); Barelli (2009); Xanthaki (2009, pp. 29-32; 34-37); UN Permanent Forum on Indigenous Peoples (2009, pp. 197-199); Xanthaki (2010, pp. 102-127); Marcelli (2011, pp. 102-115); Mereminskaya (2011, pp. 225-228); Sieder (2011, pp. 309-312); Gaete (2012, pp. 88-94); Hervé y Pérez (2012, pp. 32-37); Olivares (2013, pp. 191-192). Ver también Gómez del Prado (2002, pp. 36-45); Thornberry (2002, pp. 370-396); Eide (2006, pp. 159-167; 189-207; 211-212); Aguilar (2007, pp. 31-40, 82-96).

50 Ver Comisión Interamericana de Derechos Humanos (2010, p. 11).

51 Ver Comisión Interamericana de Derechos Humanos (2010, pp. 11-2).

Ver también Wiessner (1999, pp. 111-112); Rinaldi (2009, pp. 228-229). 
colectividades humanas, los pueblos indígenas y tribales tienen su propia trayectoria social, que se adapta al cambio de los tiempos, manteniendo en todo o en parte el legado cultural de sus ancestros. ${ }^{52}$

El Convenio 169 de la OIT combina en su Artículo 1 un conjunto de elementos objetivos, conformado por características sociales, culturales y económicas que lo diferencian del resto de la población, con un elemento subjetivo, compuesto por la autoidentificación de los pueblos indígenas y tribales como tales..$^{53}$ Dichos elementos concuerdan, en gran medida, con las pautas propuestas por el estudio de Martínez Cobo unos años antes. ${ }^{54}$ La Comisión ha reconocido abiertamente que "ni los instrumentos interamericanos de derechos humanos, ni la jurisprudencia de los órganos interamericanos de protección, han establecido con exactitud los criterios para constituir un 'pueblo indígena'", por lo que se tendría que recurrir al Artículo 1 del Convenio 169 de la OIT y al artículo 33.1 de la Declaración de la ONU sobre los Derechos de los Pueblos Indígenas . ${ }^{55}$ No obstante, esta última disposición apenas menciona el elemento subjetivo del Artículo 1 del Convenio 169 de la OIT.

\section{Dudas persistentes}

Si no hay claridad respecto a la noción de pueblos indígenas y tribales que sigue la Corte Interamericana, tampoco la hay en relación con lo que entiende por sus tierras y territorios ancestrales o tradicionales. El Tribunal ha hecho numerosas referencias a las tierras y los territorios indígenas y tribales, en algunos casos con citas al Convenio $N^{\circ} 169$, la Declaración de la ONU sobre los Derechos de los Pueblos Indígenas y otros instrumentos internacionales, sin especificar en qué consisten unas y otros. ${ }^{56}$ ¿Se debe

52 Ver Comisión Interamericana de Derechos Humanos (2010, p. 12).

53 Ver Bengoa (2007, p. 274); Mereminskaya (2011, p. 233); Marcelli (2011, pp. 31-7).

54 Ver Eide (2006, pp. 186-8); Henriksen (2008, pp. 6-7); UN Permanent Forum on Indigenous Peoples (2009, pp. 6-7).

55 Ver Comisión Interamericana de Derechos Humanos (2010, pp. 10-2).

56 Ver e.g. Corte Interamericana de Derechos Humanos (2001b, párs. 140-141, 149-151, 153; 2005a, párrs. 122, 126, 128, 130-134; 2005b, párrs. 120-122, 124, 131-137, 140-143, 146-147, 149-152, 154-155; 2006b, párrs. 113-115, 118-122, 124, 126-135, 137-140, 143; 2007, párrs. 87, 
entender que la diferencia entre estas tierras y territorios se conforma a los parámetros de los instrumentos jurídicos que cita? Distinguir entre tierras y territorios indígenas y tribales no es fácil. El empleo de estos términos en el Derecho Internacional proviene del Convenio $N^{\circ} 107$ de la OIT de 1957, sobre Pueblos Indígenas y Tribales. ${ }^{57}$ Desde entonces, la relación entre las concepciones de territorios y tierras ha sido de género a especie. Los territorios son áreas geográficas difusas, cuya ocupación y utilización las vincula no solo con la historia de un pueblo indígena o tribal, sino con su cultura e identidad como tal. Las tierras, en cambio, son áreas geográficas más delimitadas, tanto física como jurídicamente. ${ }^{58}$ En otras palabras, los territorios corresponderían al hábitat y las tierras a la parte de este que sería apropiable. ${ }^{59}$ El Artículo 13.2 del Convenio $N^{\circ} 169$ de la OIT señala que "[lla utilización del término tierras en los artículos 15 y 16 deberá incluir el concepto de territorios, lo que cubre la totalidad del hábitat de las regiones que los pueblos interesados ocupan o utilizan de alguna otra manera". El Artículo 15 de dicho Tratado se refiere al derecho de los pueblos indígenas y tribales a participar en la utilización, administración y conservación de los recursos naturales existentes en sus tierras y territorios y el Artículo 16 al derecho a no ser trasladados de ellos. ${ }^{60} \mathrm{El}$ hecho de que la jurisprudencia

88, 90-91, 94-96, 98-103, 105-108, 110-111, 114-131, 133-143, 146-147, 149-150, 153-159, 164, 167, 172, 174, 176, 178; 2010a, párrs. 51-56, 58, 60, 62-63, 67-72, 74, 76-77, 80, 84-96, 98-123, 125-126, 128-129, 132, 136-137, 142-144, 146-155, 157-158, 160, 162-167, 169-172, 174-177, 180, 182; 2012a, párrs. 124, 126-128, 134-135, 137, 145-150, 152, 154-159, 163-164, 167, 169-172, 174-177, 180, 183, 187-190, 194, 196, 203, 205-6, 211-212, 218, 229, 232; 2013b, párrs. 339-348, 351, 354-355, 406-407, 410; 2014a, párrs. 107-125, 127-129, 130-139, 141-142, 145-147, 149, 151-3, 155-163, 166, 170-172, 179, 184, 188-189, 191, 193-195, 199-201, 203).

57 El Convenio № 107 de la OIT, sobre Pueblos Indígenas y Tribales, entró en vigencia en 1959.

Con la adopción del Convenio N 169 de la OIT en 1989, el Convenio № 107 dejó de estar abierto a ratificación. Sin embargo, todavía está vigente para dieciocho Estados. La información relativa a la ratificación del Convenio $\mathrm{N}^{\circ} 107$ de la OIT está disponible en http://www.ilo.org/dyn/ normlex/en/f?p=NORMLEXPUB:11300:0::NO:11300:P11300_INSTRUMENT_ID:312252:NO

Sobre el Convenio № 107 ver Thornberry (2002, pp. 320-338); Anaya (2004, pp. 53-61; 226-228); Aguilar (2007, pp. 44-62); Dannenmaier (2008, pp. 69-70); UN Permanent Forum on Indigenous Peoples (2009, pp. 200-201); Xanthaki (2010, pp. 49-67). Ver en general Rodríguez-Piñero (2005).

58 Ver Aguilar (2007, pp. 523-31); Rodríguez Garavito y Morris (2010, pp. 43-4). Ver también Berraondo (2006, pp. 477-87). pp. 80-2).

59 Ver Gómez (2006, p. 140); Bengoa (2007, p. 275); Fernández y De la Piedra (2011,

60 Ver Berraondo (2006, pp. 472-7).

Sobre la distinción entre tierras y territorios en el Convenio $N^{\circ} 169$ de la OIT y los derechos 
interamericana no diferencie las tierras de los territorios, transformando esta distinción en ociosa, quizás provenga de una lectura poco cuidadosa de tales disposiciones del Convenio $\mathrm{N}^{\circ} 169$. En efecto, la Corte reconoce a los pueblos indígenas y tribales el derecho de consulta y el de propiedad comunal sobre sus tierras y territorios. Esto, en la medida en que dichas tierras y territorios puedan ser calificados como ancestrales o tradicionales, cualidad que se refiere más al modo que al tiempo de su tenencia y utilización, puesto que exige una conexión distintiva con el pueblo respectivo. ${ }^{61}$ Como lo ha reiterado la Corte, tierras y territorios son esenciales no solo a la identidad cultural de los pueblos indígenas y tribales, sino a su supervivencia como entes colectivos. Según el Tribunal, determinar cuáles son las tierras y los territorios tradicionales de una comunidad indígena $\mathrm{o}$ tribal no es algo que le compete hacer a la Corte, "pero sí establecer si el Estado ha respetado y garantizado el derecho a la propiedad comunal de sus miembros". ${ }^{62}$

A este respecto, la Comisión Interamericana se ha referido al Convenio $N^{\circ} 169$ de la OIT, en particular a su Artículo 13.2. ${ }^{63}$ Con apoyo en esta disposición, la Comisión señaló que "[i]ntegralmente, las tierras y los recursos naturales que en ellas se contienen conforman la noción jurídica de 'territorio', tal como lo ha confirmado la Corte Interamericana". ${ }^{64}$ En este punto, la Comisión citó a Saramaka, en donde el Tribunal internacional indicó que "[all hacer referencia al término 'territorio' la Corte se

sobre ellos que la parte II de este tratado les otorga a los pueblos indígenas y tribales, ver Montt y Matta (2011, pp. 197-203). Ver también Swepston (1990, pp. 696-710); Organización Internacional del Trabajo (2009, pp. 91-105; 107-115).

61 Ver Schettini (2012, p. 73); Dulitzky (2010, pp. 34, 42).

La conexión distintiva, particular o única sería una categoría propia del derecho de propiedad comunal indígena y tribal, consistente en el profundo significado social, cultural y espiritual que le atribuyen estos pueblos a sus tierras, territorios y recursos naturales. Como tal, escaparía a las categorías existentes en los sistemas jurídicos provenientes de las familias europeas del Common Law y del Civil Law.

Ver Dannenmaier (2008).

Sobre los inconvenientes de este enfoque socio-cultural a los reclamos de propiedad colectiva ver Dulitzky (2010, pp. 42-8). Ver también Dulitzky (2010, pp. 48-79).

62 Corte Interamericana de Derechos Humanos (2005b, párr. 215). Ver Corte Interamericana de Derechos Humanos (2006a, párrs. 22-23, 26). Ver también Corte Interamericana de Derechos Humanos (2006, párrs. 24-25).

63 Ver Comisión Interamericana de Derechos Humanos (2010, p. 14).

64 Ver Comisión Interamericana de Derechos Humanos (2010, p. 13-4). Ver también Organización Internacional del Trabajo (2009, pp.91-105). 
refiere a la totalidad de tierra y recursos que los Saramaka han utilizado tradicionalmente". ${ }^{65}$ Esta interpretación poco se aleja del empleo de dichos términos en la Declaración de la ONU sobre los Derechos de los Pueblos Indígenas. ${ }^{66}$ Nada de lo anterior permite a los Estados parte del Pacto de San José de Costa Rica identificar tales tierras y territorios, sobre los cuales los pueblos indígenas y tribales tienen derechos de propiedad colectiva y consulta, por lo que esta determinación queda en manos de las mismas comunidades beneficiadas y de los testigos y peritos que acrediten esta calidad, quienes son generalmente suministrados por los que apoyan las peticiones comunitarias ante el Estado respetivo y la Corte Interamericana.

La indeterminación conceptual sobre la que la Corte ha construido su jurisprudencia acerca de la propiedad comunal no se restringe a las nociones de pueblos, tierras y territorios indígenas y tribales. En Operación Génesis, el Tribunal no especificó si Colombia privó, limitó o restringió el derecho de propiedad colectiva de las comunidades afrodescendientes del Cacarica; solo indicó que el Estado demandado afectó o violó este derecho consagrado en el Artículo 21. ${ }^{67}$ Como otras de sus sentencias sobre pueblos indígenas y tribales, la Corte habló de violaciones de la propiedad comunal sin especificar si estas adoptaron la forma de privaciones o de limitaciones o restricciones a este derecho. ${ }^{68}$ Algo parecido ha ocurrido respecto a la jurisprudencia interamericana sobre propiedad individual de simples particulares, donde el Tribunal ha calificado el incumplimiento del Artículo 21 como afectaciones, vulneraciones, violaciones o privaciones contrarias a esta disposición. ${ }^{69}$ La Corte Interamericana ha citado la jurisprudencia de la

65 Ver Comisión Interamericana de Derechos Humanos (2010, pp. 13-4). Ver también Corte Interamericana de Derechos Humanos (2007, nota 63 en párr. 82).

66 Ver Preámbulo y Artículos. 8, 10, 25, 26, 27, 28, 29, 30 y 32 de la Declaración de la ONU sobre los Derechos de los Pueblos Indígena.

67 Ver Corte Interamericana de Derechos Humanos (2013b, párrs. 352-353, 357-358, 486).

68 Ver Corte Interamericana de Derechos Humanos (2001b, párrs. 155, 173; 2004a, párrs. 47, 52; 2005a, párrs. 135, 233; 2005b, párrs. 156, 242; 2006b, párrs. 144, 248; 2007, párrs. 154, 156, 158, 214; 2010a, párrs. 170, 182, 337; 2012a, párrs. 232, 341). Ver también Corte Interamericana de Derechos Humanos (2014a, párrs. 137, 145-146).

69 Ver Corte Interamericana de Derechos Humanos (2001 a, párrs. 129-131, 191; 2003, párrs. 115, 121, 187; 2004b, párrs. 220-221, 280; 2005c, párrs. 108, 111, 269; 2006c, párrs. 182-5, 187, 200, 426; 2008a, párrs. 114-118, 135; 2008d, párrs. 195, 199, 204, 209, 214, 218, 289; 2009, párrs. 90-91, 158; 2011 a, párrs. 84-85, 146; 2011b, párrs. 149-151, 393; 2012b, párrs. 223, 335; 2012c, párrs. 168, 175-177, 180-182, 195, 202-203, 206-207, 403; 2012d, párrs. 282, 350; 2013a, párrs. $178,180-181,183,233)$. 
Corte Europea de Derechos Humanos relativa a interferencias a la propiedad, pero no ha recogido las tres categorías que ese Tribunal ha distinguido a partir del texto del Artículo 1 del Primer Protocolo de 1952, adicional al Convenio Europeo para la Protección de los Derechos Humanos y de las Libertades Fundamentales de $1950 .{ }^{70}$ A partir de Yakye Axa, algunos de los criterios desarrollados en el Sistema Europeo de Derechos Humanos han sido utilizados por la Corte Interamericana para establecer las cuatro pautas que deben cumplir las medidas estatales que limiten o restrinjan el derecho de propiedad, sea de carácter individual o comunal: legalidad, necesidad, proporcionalidad e interés público. ${ }^{71}$ En Saramaka, el Tribunal agregó una quinta pauta, exclusiva para la propiedad colectiva: la subsistencia del pueblo indígena o tribal respectivo. ${ }^{72} \mathrm{~A}$ fin de evitar que una medida que limite o restrinja el derecho de propiedad comunal constituya una denegación de la subsistencia de aquel pueblo, el Estado correspondiente debe cumplir las tres salvaguardas mencionadas en Saramaka y Kichwa de Sarayaku, consistentes en asegurar: la participación efectiva de los integrantes de la comunidad indígena o tribal, de acuerdo con sus costumbres y tradiciones; que estos obtengan un beneficio razonable del proyecto que se realice dentro de su territorio; y que no se adoptará ninguna medida dentro de su territorio sin que entidades técnicas independientes lleven a cabo un estudio previo de impacto social y ambiental, bajo supervisión del Estado. ${ }^{73}$ Salvo la quinta pauta compuesta por estas tres salvaguardas, la Corte Interamericana no ha explicado los patrones de conducta que se espera de los Estados parte del Pacto de San José de Costa Rica más que

70 Ver López Escarcena (2015, pp. 531-76).

La Convención Europea de Derechos Humanos entró en vigor en 1953.

Sobre las privaciones de la propiedad, controles en su uso y otras interferencias a este derecho en el sistema europeo ver Van Dijk, Van Hoof, Van Rijn y Zwaak (2006, pp. 863-893); Harris, O'Boyle, Warbrick, Bates (2009, pp. 655-696); White y Ovey (2010, pp. 477-505). Ver también López Escarcena (2012).

71 Ver Corte Interamericana de Derechos Humanos (2005b, párrs. 144-9; 2006b, párrs. 1389; 2008a, párrs. 60-5, 73-76, 90, 96, 98, 113-118; 2012b, párrs. 217, 220, 222-223; 2013a, párrs. 180-181, 183). Ver también Corte Interamericana de Derechos Humanos (2008b, pp. 1-3; 2008d, párrs. 174, 188-189, 193, 195, 197, 199; 2014b, párrs. 20-23). 156-157).

72 Ver Corte Interamericana de Derechos Humanos (2007, párrs. 127-129; 2012a, párrs.

73 Ver Corte Interamericana de Derechos Humanos (2007, párrs. 129, 143). Ver también Corte Interamericana de Derechos Humanos (2008c, párrs. 15, 17-19, 22; 2012a, párr. 157; 2014b, párr. 25). 
de manera imprecisa, dificultando su seguimiento por los mismos. Este no es un problema menor, considerando que en caso de conflicto entre el derecho de propiedad individual y el derecho de propiedad colectiva, el Tribunal ha dado a entender que por regla general debe favorecerse al primero sobre el segundo. ${ }^{74} \mathrm{Si}$ bien va a corresponder a los tribunales internos definir cuándo prevalece el derecho individual y cuándo el comunal, la Corte Interamericana podrá revisar esta determinación, a fin de dilucidar si el Estado al que pertenecen estos tribunales efectivamente respetó los derechos humanos de los integrantes del pueblo indígena o tribal correspondiente. ${ }^{75}$ En este contexto, solo razones concretas y justificadas servirán de excusa para no devolver las tierras y los territorios ancestrales. Este es el único evento en el que los Estados parte de la Convención Americana podrán buscar una propiedad equivalente en calidad y extensión o pagar una justa indemnización; en ambos casos, previa consulta a los miembros del pueblo respectivo. ${ }^{76}$

\section{Conclusión}

La Corte Interamericana de Derechos Humanos se ha referido a la propiedad colectiva de los pueblos indígenas y tribales en diversas oportunidades. Sus sentencias en Awas Tingni, Moiwana, Yakye Axa, Sawhoyamaxa, Saramaka, Xákmok Kásek y Kichwa de Sarayaku han llevado a varios autores a pronunciarse sobre este derecho jurisprudencial. Con excepciones, estas publicaciones académicas comparten un tono acrítico e incluso apologético del trabajo del Tribunal en el tema. Por lo mismo, suelen evitar cuestionar los criterios jurisprudenciales sobre los que se es-

74 Ver Corte Interamericana de Derechos Humanos (2005b, párrs. 146-149; 2007, párrs. 127132; 2010a, párr. 149; 2012a, párrs. 156-157). Ver también Rodríguez-Piñero (2006, pp. 192-195); Nikken (2009, pp. 262-264); Weckel y Rinaldi (2008, pp. 429-430); Rinaldi (2009, pp. 236-238); Salmón (2011, pp. 217-219); Pentassuglia (2011, pp. 173-174; 178-179). Cf. Pasqualucci (2009, pp. 79-91; 97-98); Dulitzky (2010, pp. 51-52); Gonza (2014, p. 52); Ruiz Chiriboga y Donoso (2014, pp. 975-980).

75 Ver Corte Interamericana de Derechos Humanos (2006b, párr. 136; 2014a, párr. 144).

76 Ver Corte Interamericana de Derechos Humanos (2005b, párr. 149; 2006b, párrs. 135, 138-139; 2014b, párrs. 24, 26-28). Ver también Rodríguez-Piñero (2006, pp. 194-195); Nash (2008, pp. 71-73); Nikken (2009, p. 264); Rinaldi (2009, p. 238). 
tructura el derecho de propiedad comunal en el sistema interamericano o la falta de ellos. No obstante, son muchas las preguntas que han quedado sin respuesta a partir de dichas sentencias de la Corte. Este artículo se ha centrado en tres: la indeterminación de las nociones de pueblo indígena y tribal, de sus tierras y territorios ancestrales o tradicionales y de las privaciones y limitaciones o restricciones al derecho de propiedad que emplea el Tribunal en su jurisprudencia. Aun cuando Operación Génesis no aclara estas dudas, permite emprender una necesaria relectura crítica de las decisiones judiciales dictadas hasta el momento por la Corte en esta materia.

Solo en algunos casos la jurisprudencia interamericana ha ofrecido indicios sobre qué constituye a un pueblo como indígena o tribal, de manera más bien equívoca. La ambigüedad de estos planteamientos entorpece la aplicación de los criterios desarrollados por este Tribunal internacional en una región caracterizada por una mezcla racial y cultural, en donde el componente aborigen americano o negro africano tiende a prevalecer. Tal jurisprudencia ha señalado, de modo muy general, cómo identificar los territorios o las tierras de los pueblos indígenas y tribales protegidos por la Convención Americana, pero al hacerlo ha utilizado indistintamente ambos términos. Así, no solo ha desdibujado sus respectivos contornos, sino que ha dado a entender que tanto el derecho de consulta como el de propiedad comunal son aplicables respecto a tierras y territorios. Esta confusión terminológica dificulta a los Estados anticipar en dónde podrían surgir controversias por supuestas violaciones a la propiedad colectiva sobre los territorios y las tierras protegidos convencionalmente. La Corte ha reconocido, además, dos formas distintas de interferencias con la propiedad comunal, sin ofrecer criterios explícitos que permitan determinar cuándo se produce una o la otra. Esto es preocupante, ya que mientras las privaciones de propiedad requieren ir acompañadas de indemnización, las limitaciones o restricciones a este derecho no necesariamente deben ser indemnizadas.

En suma, la jurisprudencia de la Corte Interamericana no ha indicado más que de forma incierta qué es un pueblo indígena o tribal y cómo pueden identificarse sus tierras y territorios ancestrales o tradicionales, ni ha explicado a la fecha qué diferencia a las privaciones de las limitaciones o restricciones que puede sufrir el derecho de propiedad colectiva de esas comunidades. Esta indeterminación obstaculiza el cumplimiento del Artículo 21 del Pacto de San José de Costa Rica por sus Estados parte. La 
concreción de estas nociones imprecisas, pero no por eso menos fundamentales, queda actualmente a cargo de los beneficiarios de la protección convencional, en particular de los testigos y peritos que les asignan a las comunidades peticionarias quienes apoyan sus solicitudes ante los Estados demandados y la Corte Interamericana.

En su jurisprudencia sobre propiedad indígena y tribal, el Tribunal ha interpretado y aplicado el Artículo 21 de la Convención Americana desde las disposiciones de tratados y declaraciones internacionales, desde las normas jurídicas y decisiones judiciales de Derecho Comparado, e incluso desde las consideraciones de informes de expertos como los relatores especiales de la ONU sobre pueblos indígenas. Es así como la Corte Interamericana ha utilizado las reglas y los principios establecidos en el Convenio № 169 de la OIT para interpretar los derechos de consulta y a la identidad cultural de los pueblos indígenas y tribales. Sería conveniente que este Tribunal emplee correctamente dichas reglas y principios, no solo respecto a estos derechos, sino también para aclarar las nociones de pueblos indígenas y tribales y de sus territorios y tierras, a fin de darles mayor precisión y así fortalecer y enriquecer su jurisprudencia sobre propiedad colectiva. Lo mismo puede decirse del uso que ha hecho la Corte Interamericana de la jurisprudencia de la Corte Europea de Derechos Humanos acerca del Artículo 1 del Primer Protocolo Adicional al Convenio para la Protección de los Derechos Humanos y de las Libertades Fundamentales, referente a las privaciones y las limitaciones o restricciones del derecho de propiedad que protege el Artículo 21 del Pacto de San José de Costa Rica. La jurisprudencia de la Corte Europea puede dar luces a su contraparte interamericana en la racionalización de una distinción que requiere ser explicitada, para facilitar la interpretación y aplicación de su tratado constitutivo en nuestro sistema regional de derechos humanos.

\section{Referencias}

Aguilar, G. (2007). Dinámica internacional de la cuestión indígena. Santiago: Librotecnia.

Aguilar, G. (ed.) (2014). Diálogo entre jurisdicciones: el desarrollo del derecho público y una nueva forma de razonar. Santiago: Librotecnia. 
Anaya, J. (2004). Indigenous Peoples in International Law. Nueva York: Oxford University Press.

Anaya, J. (2005). Indigenous Peoples' Participatory Rights in Relation to Decisions about Natural Resource Extraction: The More Fundamental Issue of What Rights Indigenous Peoples Have in Lands and Resources. Arizona Journal of International and Comparative Law, 22, 7-17.

Anaya, J. y Williams, R. (2001). The Protection of Indigenous Peoples' Rights over Lands and Natural Resources under the Inter-American Human Rights System. Harvard Human Rights Journal, 14, 33-86.

Barelli, M. (2009). The Role of Soft Law in the International Legal System: the Case of the United Nations Declaration on the Rights of Indigenous Peoples. International \& Comparative Law Quarterly, 58, 957-983.

Bengoa, J. (2007). La emergencia indígena en América Latina. Santiago: Fondo de Cultura Económica.

Berraondo, M. (2006). Tierras y territorios como elementos sustantivos del derecho humano al medio ambiente. En M. Berraondo (ed.), Pueblos indigenas y derechos humanos (pp. 469-487). Bilbao: Universidad de Deusto.

Bjorge, E. (2014). The Evolutionary Interpretation of Treaties. Oxford: Oxford University Press.

Burgorgue-Larsen, L. (2013). El diálogo judicial. Máximo desafio de los tiempos jurídicos modernos. México D. F.: Porrúa.

Comisión Interamericana de Derechos Humanos. (2010). Derechos de los pueblos indigenas $y$ tribales sobre sus tierras ancestrales y recursos naturales: normas y jurisprudencia del sistema interamericano de derechos humanos. Washington: OEA.

Commission, J. (2007). Precedent in Investment Treaty Arbitration. A Citation Analysis of a Developing Jurisprudence. Journal of International Arbitration, 24(2), 129-158.

Dannenmaier, E. (2008). Beyond Indigenous Property Rights: Exploring the Emergence of a Distinctive Connection Doctrine. Washington University Law Review, 86, 53-110.

Del Toro, M. (2010). El derecho de propiedad colectiva de los miembros de comunidades y pueblos indígenas en la jurisprudencia de la Corte Interamericana de Derechos Humanos. Anuario Mexicano de Derecho Internacional, 10, 49-95.

Dhommeaux, J. (2009) Les communautés autochtones et tribales dans la jurisprudence de la Cour Interaméricaine des Droits de 1`Homme. En L. Hennebel y H. Tigroudja (eds.), Le particularisme interaméricain des droits de rhomme: en rhonneur du 40e anniversaire de la Convention Américaine des Droits de r Homme (pp. 181-213). París: Editions A. Pedone. 
Dulitzky, A. (2010). When Afro-Descendents became 'Tribal Peoples': The InterAmerican Human Rights System and Rural Black Communities. UCLA Journal of International Law and Foreign Affairs, 15(1), 29-81.

Eide, A. (2006). Rights of Indigenous Peoples -Achievements in International Law during the Last Quarter of a Century. Netherlands Yearbook of International Law, 37, 155-212.

Fernández, A. y De la Piedra, C. (2011). Implementación y evolución de los derechos contenidos en el Convenio OIT 169: aporte de la jurisprudencia y pronóstico de desarrollo futuro de sus implicancias ambientales y regulatorias. Estudios Públicos, 121, 71-132.

Ferrer, E. y Herrera, A. (eds.) (2013). Diálogo jurisprudencial en derechos humanos: entre tribunales constitucionales y cortes internacionales. Valencia: Tirant lo Blanch.

Forero, F. (2010). Conectividad: alcances del derecho a la propiedad aborigen y tribal en la jurisprudencia de la Corte Interamericana de Derechos Humanos. International Law. Revista Colombiana de Derecho Internacional, (16), 177-211.

Gaete, L. (2012). El Convenio $N^{\circ} 169$. Un análisis de sus categorías problemáticas a la luz de su historia normativa. Ius et Praxis, 18(2), 78-84.

Gajardo, J. (2014). Nuevas perspectivas de los derechos de los grupos a partir del análisis de la jurisprudencia de la Corte Interamericana de Derechos Humanos sobre los derechos de los pueblos indígenas. Tribuna Internacional, 3(5), 43-64.

Gómez del Prado, J. L. (2002). Pueblos indígenas. Normas internacionales y marcos nacionales. Bilbao: Universidad de Deusto.

Gómez, M. (2006). El Convenio 169 de la Organización Internacional del Trabajo. En M. Berraondo (ed.), Pueblos indigenas y derechos humanos (pp. 133-151). Bilbao: Universidad de Deusto.

Gonza, A. (2014). Artículo 21. Derecho a la propiedad privada. En C. Steiner y P. Uribe (eds.), Convención Americana sobre Derechos Humanos: comentario (pp. 503-530). La Paz: Fundación Konrad Adenauer.

Harris, D, O'Boyle, M., Warbrick, C. y Bates, E. (2009). Law of the European Convention on Human Rights. Oxford: Oxford University Press.

Henriksen, J. (2008). Key Principles in Implementing ILO Convention N ${ }^{0} 169$. Ginebra: OIT.

Hervé, D. y Pérez, S. (2012). Adecuación de la legislación interna a los estándares impuestos para la administración de recursos naturales. En J. Contesse (ed.), El Convenio 169 de la OIT y el Derecho chileno. Mecanismos y obstáculos para su implementación (pp. 15-101). Santiago: Universidad Diego Portales. 
Kingsbury, B. (1998). 'Indigenous Peoples' in International Law: A Constructivist Approach to the Asian Controversy. American Journal of International Law, 92(2), 414-457.

López Escarcena, S. (2012). Interferences with Property under European Human

Rights Law. Florida Journal of International Law, 24(3), 513-544.

López Escarcena, S. (2014). Indirect Expropriation in International Law. Cheltenham:

Edward Elgar Publishing.

López Escarcena, S. (2015). La propiedad y su privación o restricción en la jurisprudencia de la Corte Interamericana. Ius et Praxis, 21(1), 531-576.

López-Murcia, J. y Maldonado, G. (2009). La protección de la propiedad de la tierra en la jurisprudencia de la Corte Interamericana de Derechos Humanos y su aplicación al caso de las comunidades campesinas en Colombia. International Law: Revista Colombiana de Derecho Internacional, (14), 71-105.

Marcelli, F. (2011). Los derechos de los pueblos indígenas. Medellín: Librería Jurídica Sánchez.

Mereminskaya, E. (2011). El Convenio 169 de la OIT sobre pueblos indígenas y tribales: Derecho Internacional y experiencias comparadas. Estudios Públicos, $121,213-276$.

Meza-Lopehandía, M. (2014). El Convenio Nº 169 sobre pueblos indígenas y tribales de la Organización Internacional del Trabajo. En J. Aylwin (ed.), Los pueblos indígenas y el derecho (pp. 337-439). Santiago: Lom Ediciones.

Montt, S. y Matta, M. (2011). Una visión panorámica al Convenio OIT 169 y su implementación en Chile. Estudios Públicos, 121, 133-212.

Nash, C. (2008). Los derechos indígenas en el sistema interamericano de derechos humanos. Inter-American and European Human Rights Journal, 1(1), 61-86.

Nash, C. (2013). El principio pro persona en la jurisprudencia de la Corte Interamericana de Derechos Humanos. En H. Nogueira (ed.), Diálogo judicial multinivel y principios interpretativos favor persona y de proporcionalidad (pp. 155-199). Santiago: Librotecnia.

Nikken, P. (2009). Balancing of Human Rights and Investment Law in the InterAmerican System of Human Rights. En P. Dupuy, F. Francioni y E. Petersmann (eds.), Human Rights in International Investment Law and Arbitration (pp. 246271). Oxford: Oxford University Press.

Nogueira, H. (ed.) (2012). El diálogo transjudicial de los tribunales constitucionales entre sí y con las cortes internacionales de derechos humanos. Santiago: Librotecnia.

Nogueira, H. (ed.) (2013). Diálogo judicial multinivel y principios interpretativos favor persona y de proporcionalidad. Santiago: Librotecnia. 
Nogueira, H. (ed.) (2014). La protección de los derechos humanos y fundamentales de acuerdo a la Constitución y el derecho internacional de los derechos humanos. Santiago: Librotecnia.

Olivares, E. (2013). Indigenous Peoples' Rights and the Extractive Industry: Jurisprudence from the Inter-American System of Human Rights. Goettingen Journal of International Law, 5(1), 187-214.

Organización Internacional del Trabajo. (2009). Los derechos de los pueblos indígenas y tribales en la práctica. Una guía sobre el Convenio $N^{\circ} 169$ de la OIT. Ginebra.

Pasqualucci, J. (2009). International Indigenous Land Rights: A Critique of the Jurisprudence of the Inter-American Court of Human Rights in Light of the United Nations Declaration on the Rights of Indigenous Peoples. Wisconsin International Law Journal, 27(1), 51-98.

Patiño, L. (2014). Fundamentos y práctica internacional del derecho a la consulta previa, libre e informada a pueblos indígenas. ACDI-Anuario Colombiano de Derecho Internacional, 7, 69-111.

Paulsson, J. (2010). The Role of Precedent in Investment Arbitration. En K. YannacaSmall (ed.), Arbitration under International Investment Agreements: A Guide to the Key Issues (pp. 699-718). Nueva York: Oxford University Press.

Pentassuglia, G. (2011). Towards a Jurisprudential Articulation of Indigenous Land Rights. European Journal of International Law, 22(1), 165-202.

De Carvalho Ramos, A. (2014a). Curso de direitos humanos. São Pablo: Editora Saraiva.

De Carvalho Ramos, A. (2014b). Teoria geral dos direitos humanos na ordem internacional. São Pablo: Editora Saraiva.

Rinaldi, K. (2009). Le droit des populations autochtones et tribales à la propriété dans le système interaméricain de protection des droits de l'homme. En L. Hennebel y H. Tigroudja (eds.), Le particularisme interaméricain des droits de Thomme: en Thonneur du 40e anniversaire de la Convention Américaine des Droits de rHomme (pp. 215-50). París: Editions A. Pedone.

Rodríguez, G. (2014). Artículo 29. Normas de interpretación. En C. Steiner y P. Uribe (eds.), Convención Americana sobre Derechos Humanos: comentario (pp. 706-714). La Paz: Fundación Konrad Adenauer.

Rodríguez Garavito, C. y Morris, M. (eds.) (2010). La consulta previa a pueblos indígenas: los estándares del derecho internacional. Bogotá: Uniandes.

Rodríguez-Piñero, L. (2005). Indigenous Peoples, Postcolonialism and International Law: the ILO Regime (1919-1989). Oxford: Oxford University Press. 
Rodríguez-Piñero, L. (2006). El sistema interamericano de derechos humanos y los pueblos indígenas. En M. Berraondo (ed.), Pueblos indigenas y derechos humanos (pp. 153-203). Bilbao: Universidad de Deusto.

Rodríguez-Piñero, L. (2013a). La sentencia de la Corte Interamericana. En F. Gómez Isa (ed.), El caso Awas Tingni. Derechos humanos entre lo local y lo global (pp. 123-138). Bilbao: Universidad de Deusto.

Rodríguez-Piñero, L. (2013b). El impacto internacional de la sentencia. En F. Gómez Isa (ed.), El caso Awas Tingni. Derechos humanos entre lo local y lo global (pp. 163-203). Bilbao: Universidad de Deusto.

Ruiz Chiriboga, O. (2006). El derecho a la identidad cultural de los pueblos indígenas y las minorías nacionales: una mirada desde el sistema interamericano. Sur. Revista Internacional de Derechos Humanos, 5, 42-69.

Ruiz Chiriboga, O. y Donoso, G. (2014). Pueblos indígenas y la Corte Interamericana de Derechos Humanos. Fondo y reparaciones. En C. Steiner y P. Uribe (eds.), Convención Americana sobre Derechos Humanos: comentario (pp. 9471026). La Paz: Fundación Konrad Adenauer.

Salmón, E. (2011). Jurisprudencia de la Corte Interamericana de Derechos Humanos. Bogotá: Universidad del Rosario.

Schettini, A. (2012). Por un nuevo paradigma de protección de los derechos de los pueblos indígenas: un análisis crítico de los parámetros establecidos por la Corte Interamericana de Derechos Humanos. Sur. Revista Internacional de Derechos Humanos, 9(17), 64-87.

Sieder, R. (2011). Pueblos indígenas y derecho(s) en América Latina. En C. Rodríguez-Garavito (ed.), El derecho en América Latina: un mapa para el pensamiento jurídico del siglo XXI (pp. 303-321). Buenos Aires: Siglo Veintiuno Editores.

Swepston, L. (1990). A New Step in the International Law on Indigenous and Tribal Peoples: The ILO Convention No 169 of 1989. Oklahoma City University Law Review, 15(3), 677-714.

Thornberry, P. (2002). Indigenous Peoples and Human Rights. Manchester: Manchester University Press.

UN Permanent Forum on Indigenous Peoples. (2009). State of the World's Indigenous Peoples. Nueva York.

Van Dijk, P., Van Hoof, F., Van Rijn, A., Zwaak, L. (eds.) (2006). Theory and Practice of the European Convention on Human Rights. Mortsel: Intersentia Publishers.

Weckel, P. y Rinaldi, K. (2008). Relativisme culturel ou universalité des droits de l'homme? La réponse donnée par la Cour Interaméricaine des Droits de l'Homme par la prise en compte des coutumes indiennes. En Société Française pour le Droit International (ed.), Droit international et diversité des cultures 
juridiques/International Law and Diversity of Legal Cultures (pp. 421-431). París: Editions A. Pedone.

Wiessner, S. (1999). Rights and Status of Indigenous Peoples: A Global International and Comparative Legal Analysis. Harvard Human Rights Journal, 12, 57-128.

Wiessner, S. (2008). Indigenous Sovereignty: A Reassessment in Light of the UN Declaration on the Rights of Indigenous People. Vanderbilt Journal of Transnational Law, 41(4), 1141-1176.

White, R. y Ovey, C. (2010). The European Convention Human Rights. Oxford: Oxford University Press.

Xanthaki, A. (2009). Indigenous Rights in International Law over the Last 10 Years and Future Developments. Melbourne Journal of International Law, 10(1) , 27-37. Xanthaki, A. (2010). Indigenous Rights and United Nations Standards: Self-determination, Culture and Land. Nueva York: Cambridge University Press.

Zalaquett, J. (2008). La Declaración de Naciones Unidas sobre Derechos de los Pueblos Indígenas. Anuario de Derechos Humanos, 4, 139-48.

\section{Jurisprudencia}

Corte Interamericana de Derechos Humanos. (2000). Comunidad Mayagna (Sumo) Awas Tingni c. Nicaragua. Serie C No 66, excepciones preliminares de 1 de febrero de 2000.

Corte Interamericana de Derechos Humanos. (2001 a). Baruch Ivcher Bronstein c. Perú. Serie C No 74, sentencia de 6 de febrero de 2001.

Corte Interamericana de Derechos Humanos. (2001b). Comunidad Mayagna (Sumo) Awas Tingni c. Nicaragua. Serie C No 79, sentencia de 31 de agosto de 2001.

Corte Interamericana de Derechos Humanos. (2003). Cinco pensionistas c. Perú. Serie C N ${ }^{\circ} 98$, sentencia de 28 de febrero de 2003.

Corte Interamericana de Derechos Humanos. (2004a). Masacre Plan de Sánchez c. Guatemala. Serie C No 105, sentencia de 29 de abril de 2004.

Corte Interamericana de Derechos Humanos. (2004b). Daniel Tibi c. Ecuador. Serie C No 114, sentencia de 7 de septiembre de 2004.

Corte Interamericana de Derechos Humanos. (2005a). Comunidad Moiwana c. Surinam. Serie C No 124, sentencia de 15 de junio de 2005.

Corte Interamericana de Derechos Humanos. (2005b). Comunidad indígena Xákmok Kásek c. Paraguay. Serie C No 214, sentencia de 17 de junio de 2005.

Corte Interamericana de Derechos Humanos. (2005c). Humberto Palamara Iribarne c. Chile. Serie C No 135, sentencia de 22 de noviembre de 2005. 
Corte Interamericana de Derechos Humanos. (2006a). Comunidad indigena Yakye Axa c. Paraguay. Serie C No 142, interpretación de 6 de febrero de 2006.

Corte Interamericana de Derechos Humanos. (2006b). Comunidad indígena Sawhoyamaxa c. Paraguay. Serie C No 146, sentencia de 29 de marzo de 2006.

Corte Interamericana de Derechos Humanos. (2006c). Masacres de Ituango c. Colombia. Serie C No 148, sentencia de 1 de junio de 2006.

Corte Interamericana de Derechos Humanos (2007). Pueblo Saramaka c. Surinam. Serie C N 172 , sentencia de 28 de noviembre de 2007.

Corte Interamericana de Derechos Humanos. (2008a). María y Julio Guillermo Salvador Chiriboga c. Ecuador. Serie C No 179, sentencia de 6 de mayo de 2008. Corte Interamericana de Derechos Humanos. (2008b). María y Julio Guillermo Salvador Chiriboga c. Ecuador. Serie C N ${ }^{\circ} 179$, voto concurrente del juez Ventura Robles, 6 de mayo de 2008.

Corte Interamericana de Derechos Humanos. (2008c). Pueblo Saramaka c. Surinam. Serie C $\mathrm{N}^{\circ} 185$, interpretación de 12 de agosto de 2008.

Corte Interamericana de Derechos Humanos. (2008d). Juan Carlos Chaparro Álvarez y Freddy Hernán Lapo Íñiguez c. Ecuador. Serie C No 189, sentencia de 26 de noviembre de 2008.

Corte Interamericana de Derechos Humanos. (2009). Alejandro Acevedo Buendía y otros (cesantes y jubilados de la Contraloría) c. Perú. Serie C No 198, sentencia de 1 de julio de 2009.

Corte Interamericana de Derechos Humanos. (2010a). Comunidad indígena Xákmok Kásek c. Paraguay, Serie C № 214, sentencia de 24 de agosto de 2010.

Corte Interamericana de Derechos Humanos. (2010b). Comunidad indígena Xákmok Kásek c. Paraguay. Serie C No 214, voto concurrente del juez Vio Grossi, 24 de agosto de 2010.

Corte Interamericana de Derechos Humanos. (2011a). Victor Abrill Alosilla y otros c. Perú. Serie C № 223, sentencia de 4 de marzo de 2011.

Corte Interamericana de Derechos Humanos. (2011b). Familia Barrios c. Venezuela. Serie C No 237, sentencia de 24 de noviembre de 2011.

Corte Interamericana de Derechos Humanos. (2012a). Pueblo indígena Kichwa de Sarayaku c. Ecuador. Serie C № 245, sentencia de 27 de junio de 2012.

Corte Interamericana de Derechos Humanos. (2012b). Sebastián Furlan y familiares c. Argentina. Serie C No 246, sentencia de 31 de agosto de 2012.

Corte Interamericana de Derechos Humanos. (2012c). Masacres de El Mozote y lugares aledaños C. El Salvador. Serie C No 252, sentencia de 25 de octubre de 2012. Corte Interamericana de Derechos Humanos. (2012d). Masacre de Santo Domingo c. Colombia. Serie C No 263, sentencia de 30 de noviembre de 2012. 
Corte Interamericana de Derechos Humanos. (2013a). Carlos y Pablo Mémoli c. Argentina. Serie C No 265, sentencia de 22 de agosto de 2013.

Corte Interamericana de Derechos Humanos. (2013b). Comunidades afrodescendientes desplazadas de la cuenca del río Cacarica (Operación Génesis) c. Colombia. Serie C No 270, sentencia de 20 de noviembre de 2013.

Corte Interamericana de Derechos Humanos. (2014a). Pueblos indígenas Kuna de Madungandí y Emberá de Bayano y sus miembros c. Panamá. Serie C № 284, sentencia de 14 de octubre de 2014.

Corte Interamericana de Derechos Humanos. (2014b). Pueblos indígenas Kuna de Madungandíy Emberá de Bayano y sus miembros c. Panamá. Serie C № 284, voto parcialmente disidente del juez Ferrer Mac-Gregor, 14 de octubre de 2014.

\section{Instrumentos jurídicos}

- Convenio Europeo para la Protección de los Derechos Humanos y de las Libertades Fundamentales de 1950.

- Protocolo Adicional al Convenio para la Protección de los Derechos Humanos y de las Libertades Fundamentales de 1952.

- Convenio № 107 de la OIT de 1957, sobre Pueblos Indígenas y Tribales.

- Convención Americana sobre Derechos Humanos de 1969.

- Convenio N 169 de la OIT de 1989, sobre Pueblos Indígenas y Tribales en Países Independientes.

- Declaración de la ONU sobre los Derechos de los Pueblos Indígenas de 2007. 